\title{
Cyclic compression stimulates osteoblast differentiation via activation of the Wnt/ $\beta$-catenin signaling pathway
}

\author{
XI CHEN $^{1,2}$, JIANMIN GUO ${ }^{2}$, YU YUAN ${ }^{2}$, ZHONGGUANG SUN $^{2}$, BINGLIN CHEN $^{2}$, \\ XIAOYANG TONG ${ }^{2}$, LINGLI ZHANG ${ }^{2}, \mathrm{CHAO} \mathrm{SHEN}^{2}$ and $\mathrm{JUN} \mathrm{ZOU}^{3}$ \\ ${ }^{1}$ School of Sports Science, Wenzhou Medical University, Wenzhou, Zhejiang 325035; \\ ${ }^{2}$ School of Kinesiology; ${ }^{3}$ Development and Planning Department, \\ Shanghai University of Sport, Shanghai 200438, P.R. China
}

Received January 20, 2016; Accepted January 23, 2017

DOI: $10.3892 / \mathrm{mmr} .2017 .6327$

\begin{abstract}
It is widely accepted that mechanical stress is an important factor in bone associated cell differentiation, including that of mesenchymal stem cells, osteoblasts and osteocytes. The present study aimed to determine the effect of mechanical cyclic compressive load on osteoblast differentiation, and whether this was associated with activation of the wingless-type (Wnt)/ $\beta$-catenin signaling pathway. Using a 3D scaffold model, MC3T3-E1 cells were exposed to cyclic compressive loading via the Flexcell-5000C ${ }^{\mathrm{TM}}$ Compression system. Sinusoidal wave magnitudes of $0.33,0.5$ and $1 \mathrm{MPa}$ were applied for 4, 6 and $8 \mathrm{~h}$, at $1 \mathrm{~Hz}$ frequency. Expression levels of genes associated with osteoblast differentiation were enhanced following compression, including alkaline phosphatase, osteocalcin, runt-related transcription factor 2 and osterix. Optimal compression was observed using a magnitude of $0.5 \mathrm{MPa}$ for $6 \mathrm{~h}$, whereas a magnitude of $1 \mathrm{MPa}$ had no effect on osteoblast differentiation, and had a negative effect when applied for prolonged time periods. Compressive loading additionally enhanced the mRNA expression levels of the Wnt/ $\beta$-catenin signaling pathway component, low density lipoprotein receptor-related protein 5 , and the protein expression levels of Wnt1, disheveled segment polarity protein-2 (DVL2) and $\beta$-catenin. By contrast, mRNA expression levels of sclerostin and the inactive form of $\beta$-catenin (phosphorylated at Ser33/37/Thr41) were reduced following compressive loading. Following compressive loading of cells, dickkopf-related protein 1 (DKK-1), an inhibitor of the Wnt signaling pathway, increased protein expression levels of the inactive form of the Wnt-associated protein, phosphorylated- $\beta$-catenin, compared with compression alone. However, DVL2 and Wnt 1 protein expression levels were unaffected, suggesting that
\end{abstract}

Correspondence to: Professor Jun Zou, Development and Planning Department, Shanghai University of Sport, 399 Changhai Road, Yangpu, Shanghai 200438, P.R. China

E-mail: zoujun777@126.com

Key words: compressive loading, osteoblast differentiation, magnitude, duration, wingless-type signaling pathway the loading-induced activation of $\mathrm{Wnt} / \beta$-catenin signaling decreased however, it was not prevented by DKK-1 treatment. In conclusion, the present study demonstrated that cyclic compressive load promoted osteoblast differentiation and may be dependent on the $\mathrm{Wnt} / \beta$-catenin signaling pathway in regard to magnitude and duration.

\section{Introduction}

Bone undergoes constant remodeling via a balance between bone formation and resorption, which maintains adult skeletal health; osteoporosis is a bone-associated disease caused by disruption of this balance. It is characterized by a reduction in bone mass or bone mineral density, and the deterioration of micro-architecture that frequently leads to a high risk of fracture $(1,2)$. Osteoblasts induce bone formation whereas osteoclasts promote bone resorption.

Mechanical loading, including strain, compression and fluid shear, are stimuli that regulate the function of osteoblasts and osteoclasts. Therefore, bone mass (3) and tissue are maintained and have sufficient strength to withstand such loads. By contrast, unloading may disrupt this balance and lead to rapid bone loss or osteoporosis. For example, astronauts may lose up to $2 \%$ in hip bone density per month in space (4). Bone cells, including osteocytes and osteoblasts, have been extensively studied in response to mechanical loading, and reports have suggested that strain or fluid shear may serve a significant role in bone development (5-7). In addition, the effect of bone cell compression has been investigated in vivo and in vitro (8-11). However, the majority of previous studies have examined the effect of mechanical load on monolayer culture. Therefore, the aim of the present study was to determine the effect of compressive load on osteoblast differentiation in a 3D model in vitro.

Mechanical force may influence biochemical signaling in osteoblasts and osteocytes by altering transcription factor translocation, gene expression and osteoblast differentiation (12). This response may be associated with various intracellular signaling pathways, including wingless-type $(\mathrm{Wnt}) / \beta$-catenin, bone morphogenetic protein (BMP), mitogen activated protein kinase and osteoprotegerin (OPG)-receptor activation of nuclear factor (NF)-КB (RANK)-RANK ligand 
(RANKL) (10). The Wnt/ $\beta$-catenin signaling pathway is important in bone biology, as it may promote osteoblast lineage differentiation of mesenchymal precursors (13-15). This may enhance osteoblast proliferation and terminal differentiation (16-18), and inhibit apoptosis of osteoblasts and osteocytes (19). Runt-related transcription factor 2 (Runx2) and osterix (Osx) are key downstream transcription factors of the $\mathrm{Wnt} / \beta$-catenin and BMP signaling pathways, and regulate osteoblast differentiation $(20,21)$. Accompanied with differentiation of osteoblasts, the expression of bone matrix proteins, alkaline phosphatase (ALP) and osteocalcin (OCN) increases, which may lead to mineralization and bone formation.

Sawakami et al (22) revealed that mice lacking the Wnt co-receptor, functional lipoprotein receptor-related protein (Lrp)5, have an impaired cortical bone response to ulna loading. A further study demonstrated that high and low magnitudes of strain enhanced $\beta$-catenin in mesenchymal stem cells, promoted osteogenesis and suppressed adipogenesis (23). Mechanical loading additionally regulates osteoblast activity via downregulation of sclerostin (SOST) and Dickkopf-related protein 1 (DKK-1) expression, which negatively regulate the Wnt signaling pathway $(9,11,24)$. Conversely, other studies reported that a high magnitude of mechanical load enhanced the expression levels of interleukin (IL)-6, IL-8, RANKL and fibroblast growth factor-2, and reduced the expression levels of OPG and ALP activity (25-28). This reduced the differentiation of osteoblasts and enhanced the activation of osteoclasts. Thus, the underlying mechanism by which magnitude and duration of cyclic compressive load affect osteoblast differentiation remains to be fully understood. The present study aimed to investigate the effect of different magnitudes and durations of cyclic compression on osteoblast differentiation and determine whether this is associated with activation of the Wnt signaling pathway.

\section{Materials and methods}

Cell culture. The mouse MC3T3-E1 osteoblast-like cell line was obtained from the American Type Culture Collection (Manassas, VA, USA; CRL-2594) and cultured in $\alpha$-modified Eagle's medium ( $\alpha$-MEM; HyClone; GE Healthcare Life Sciences, Logan, UT, USA) supplemented with $10 \%$ fetal bovine serum (FBS; Gibco; Thermo Fisher Scientific, Inc., Waltham, MA, USA), and $1 \%$ penicillin and streptomycin (P/S; Beyotime Institute of Biotechnology, Haimen, China). Cells were cultured in a humidified incubator at $37^{\circ} \mathrm{C}$ and $5 \% \mathrm{CO}_{2}$. Cells were passaged at $70-80 \%$ confluence using $0.25 \%$ trypsin-EDTA (Beyotime Institute of Biotechnology).

$3 D$ scaffold preparation. Confluent cells were detached using $0.25 \%$ trypsin-EDTA and counted. Cells were suspended at $4 \times 10^{7}$ cells $/ \mathrm{ml}$ in $2 \mathrm{X} \alpha$-MEM containing $20 \% \mathrm{FBS}$ and $2 \% \mathrm{P} / \mathrm{S}$, prior to mixing with an equal volume of $4 \%$ low melting point agarose (cat. no. A9045; Sigma; Merck KGaA, Darmstadt, Germany) at $37^{\circ} \mathrm{C}$. The mixture was added to 6-well Biopress ${ }^{\mathrm{TM}}$ compression culture plates (Flexcell International Corporation, Burlington, NC, USA) and allowed to set at room temperature. The resulting $3 \times 5 \mathrm{~mm}$ cylinder agarose gel containing $2 \times 10^{7}$ cells $/ \mathrm{cm}^{3}$ established the $3 \mathrm{D}$ scaffold model. Cells within the $3 \mathrm{D}$ scaffolds were cultured in $1 \mathrm{X} \alpha$-MEM. During the cyclic compression experiment, $50 \mathrm{mg} / \mathrm{ml}$ ascorbic acid and $10 \mathrm{mM} \beta$-glycerophosphate were added to the medium.

Cyclic compression experiments. Following $20 \mathrm{~h}$ incubation of the 3D scaffold, the Flexcell-5000C ${ }^{\mathrm{TM}}$ Compression system (Flexcell International Corporation) was utilized to apply the compressive load. Previously published data revealed that $6 \%$ compressive force corresponds to $1 \mathrm{MPa}$ (29). Therefore, the present study used a sinusoidal wave with 0.33 , 0.5 and $1 \mathrm{MPa}$ (equivalent to 2,3 and 6\% magnitude) and $1 \mathrm{~Hz}$ frequency $(25,29)$. Unloaded 3D scaffold samples served as controls. Samples were analyzed at 4,6 and 8 h. To determine whether the $\mathrm{Wnt} / \beta$-catenin signaling pathway was involved in the osteoblast response to mechanical compression, an inhibitor of Wnt signaling, DKK-1 (50 ng/ml), was added to the $1 \mathrm{X}$ culture medium $1 \mathrm{~h}$ prior to compressive loading (6 $\mathrm{h}$ and $0.5 \mathrm{MPa})$.

ALP assay. Following cyclic compression, cell-gel samples were washed 3 times with phosphate-buffered saline (PBS) and homogenized with $1 \mathrm{ml} 0.3 \%$ Triton X-100. ALP activity was quantified in the gel supernatants with the Alkaline Phosphatase assay kit (Beyotime Institute of Biotechnology), according to the manufacturer's protocol, using para-nitrophenol as a substrate, as previously described (30).

$R N A$ extraction and reverse transcription-quantitative polymerase chain reaction ( $R T-q P C R)$. Following compressive loading, total RNA was isolated from cell-gel samples using TRIzol $^{\circledR}$ (Invitrogen; Thermo Fisher Scientific, Inc.) according to the manufacturer's protocol. RNA purity and concentration were determined by measuring the absorbance at wavelengths of 260 and $280 \mathrm{~nm}$. cDNA was obtained by RT using the PrimeScript ${ }^{\circledR}$ kit (Takara Bio, Inc., Otsu, Japan). qPCR was subsequently performed with the FastStart SYBR ${ }^{\circledR}$-Green Master kit (Roche Applied Science, Mannhein, Germany) on an ABI 7300 Real-Time PCR system (Applied Biosystems; Thermo Fisher Scientific, Inc.) with 40 cycles of $94^{\circ} \mathrm{C}$ for $30 \mathrm{sec}$ and $60^{\circ} \mathrm{C}$ for $90 \mathrm{sec}$. Forward and reverse PCR primers were designed based on mouse sequence information, and are listed in Table I. The quantitation cycle $(\mathrm{Cq})$ value was calculated for gene expression quantification using the $2^{-\Delta \Delta C q}$ method (31). GAPDH served as an internal standard.

Western blot analysis. Following compressive loading, cell-gel samples were washed in PBS. Total protein was extracted using radioimmunoprecipitation assay lysis buffer (Beyotime Institute of Biotechnology). The protein concentration was determined in each sample using the Bicichoninic Acid Protein assay kit (Beyotime Institute of Biotechnology). A total of $20 \mathrm{ml}$ of each sample was loaded onto 8 to $10 \%$ gels and subjected to sodium dodecyl sulfate-polyacrylamide gel electrophoresis, prior to transfer onto polyvinylidene difluoride membranes (EMD Millipore, Billerica, MA, USA) via electroblotting. Membranes were blocked for $1 \mathrm{~h}$ with $5 \%$ fat-free milk in Tris-HCl-buffered saline containing 0.1\% Tween-20 (TBST) at room temperature. Subsequently, membranes were probed with the following primary antibodies: Rabbit anti-phosphorylated (p)- $\beta$-catenin (dilution, 1:800; catalog 
no. 9561; Cell Signaling Technology, Inc., Danvers, MA, USA), rabbit anti- $\beta$-catenin (dilution, 1:1,000; catalog no. ab6302; Abcam, Cambridge, MA, USA), rabbit anti-Wnt1 (dilution, 1:1,000; catalog no. ab15251; Abcam), rabbit anti- $\beta$-actin (dilution, 1:1,000; catalog no. 4970; Cell Signaling Technology, Inc.) and rabbit anti-disheveled segment polarity protein-2 (DVL2; dilution, 1:1,500; catalog no. 12037-1-AP; ProteinTech Group, Inc., Chicago, IL, USA) at $4^{\circ} \mathrm{C}$ overnight. Following washing with TBST, membranes were incubated with a horseradish peroxidase-conjugated goat anti-rabbit IgG secondary antibody (dilution, 1:5,000; catalog no. 7074; Cell Signaling Technology, Inc.) for $2 \mathrm{~h}$ at room temperature. An Enhanced Chemiluminescence Detection kit (EMD Millipore) was used to detect the immunoreactive signals, which were exposed using the Tanon 5200 Multi system (Tanon Science and Technology Co., Ltd., Shanghai, China). Protein bands were quantified using Image J software version 1.49 (National Institutes of Health, Bethesda, MD, USA).

Statistical analysis. Data are expressed as the mean \pm standard deviation of three independent experiments. Figures were prepared using GraphPad Prism software version 5.01 (GraphPad Software, Inc., La Jolla, CA, USA). Two-way analysis of variance followed by the Bonferroni post hoc test was performed to determine the effect of cyclic compression magnitude and duration on osteoblast differentiation. Statistical calculations were performed using SPSS software version 13.0 (SPSS, Inc., Chicago, IL, USA), and P<0.05 was considered to indicate a statistically significant difference.

\section{Results}

Mechanical compressive load stimulates osteoblast differentiation. ALP and OCN are indicators of early and late osteoblast differentiation, respectively. The present study revealed that $0.5 \mathrm{MPa}$ compression significantly increased expression of ALP activity by 4.40 -fold after $6 \mathrm{~h}$ compared with cells at $0 \mathrm{~h}(\mathrm{P}<0.01)$. In addition, compared with cells at $0 \mathrm{~h}$, a 2.57 -fold increase in ALP activity was observed following $0.33 \mathrm{MPa}$ compression for $6 \mathrm{~h}(\mathrm{P}<0.01)$, whereas $1 \mathrm{MPa}$ induced a significant reduction in ALP activity after $8 \mathrm{~h}(\mathrm{P}<0.01$; Fig. 1A).

Similarly, compression of cells induced a significant increase in the mRNA expression levels of $A L P$ (Fig. 1B) and $O C N$ (Fig. 1C), particularly following treatment with $0.5 \mathrm{MPa}$ for $6 \mathrm{~h}(\mathrm{P}<0.01)$. In addition, a significant increase in $A L P$ mRNA expression levels was observed following treatment with $0.33 \mathrm{MPa}$ for $6 \mathrm{~h}(\mathrm{P}<0.01)$; however, no significant increase in $O C N$ expression levels were observed under this condition. Conversely, application of $1 \mathrm{MPa}$ significantly reduced the expression levels of $A L P$ (Fig. 1B) and $O C N$ (Fig. 1C) after $8 \mathrm{~h}$ $(\mathrm{P}<0.01)$. These results indicated that the ability of compressive load to stimulate osteoblast differentiation is dependent on the duration and magnitude of the force applied.

Mechanical compressive load increases the expression of key transcription factors involved in osteoblast differentiation. Runx2 and Osx are transcription factors involved in osteoblast differentiation. Consistent with ALP activity and mRNA expression levels, $6 \mathrm{~h}$ compression at magnitude of $0.5 \mathrm{MPa}$
Table I. Primer sequences.

Gene

Primer sequence (5'-3')

\begin{tabular}{ll}
\hline$A L P \_F$ & ACTGGCTGTGCTCTCCCTAC \\
$A L P \_R$ & GACCTCTCCCTTGAGTGTGG \\
$O C N \_F$ & CAGGGAGGCAGTGACTCTTC \\
$O C N \_R$ & AGTGTGGAAAGTGTGGAGTT \\
$R u n x 2_{2} F$ & GGTGAAACTCTTGCCTCGTC \\
$R u n x 2_{-} R$ & AGTCCCAACTTCCTGTGCT \\
$O s x \_F$ & TGGTACAAGGCAGGCATCCA \\
$O s x \_R$ & GGAGCAAAGTCAGATGGGTAAGT \\
$L r p 5 \_F$ & GAGCACGTGATTGAGTTTG \\
$L r p 5 \_R$ & TCAGTCCAGTAGATGTAGC \\
$S O S T \_F$ & GAAGGGAGTGTGGAACGAAAG \\
$S O S T \_R$ & CCAGGTCAGGGTCAGAAACC \\
$G A P D H \_F$ & GACAACTTTGGCATTGTGGA \\
$G A P D H \_R$ & ATGCAGGGATGATGTTCTGG
\end{tabular}

ALP, alkaline phosphatase; OCN, osteocalcin; Runx2, runt-related transcription factor 2; Osx, osterix; Lrp5, low density lipoprotein receptor-related protein 5; SOST, sclerostin; F, forward; R, reverse.

induced the greatest increase in Runx2 $(\mathrm{P}<0.01$; Fig. 1D) and $O s x(\mathrm{P}<0.05$; Fig. 1E) mRNA expression levels by $8.44-$ and 2.51-fold, respectively, compared with the $0 \mathrm{~h}$ control. Application of $0.33 \mathrm{MPa}$ did not significantly alter Runx2 and Os $x$ mRNA expression levels. Compression at $1 \mathrm{MPa}$ induced a significant increase in the mRNA expression levels of Runx2 after $6 \mathrm{~h}(\mathrm{P}<0.01)$, whereas mRNA expression levels of $O s x$ were reduced after $8 \mathrm{~h}(\mathrm{P}<0.05)$. Thus, $0.5 \mathrm{MPa}$ compressive load for $6 \mathrm{~h}$ increased the mRNA expression levels of key transcription factors, suggesting that osteoblast differentiation was enhanced in MC3T3-E1 cells.

Mechanical compressive load stimulates osteoblast differentiation via the Wnt/ $\beta$-catenin signaling pathway. The present study examined whether $\mathrm{Wnt} / \beta$-catenin signaling was involved in compression-induced regulation of osteoblast differentiation. Compared with cells at $0 \mathrm{~h}$, a compressive load of $0.5 \mathrm{MPa}$ significantly enhanced the mRNA expression levels of $\operatorname{Lrp} 5$ at $6 \mathrm{~h}(\mathrm{P}<0.01$; Fig. 2A), and reduced SOST mRNA expression levels at 4 and $6 \mathrm{~h}(\mathrm{P}<0.01$; Fig. $2 \mathrm{~B})$. In addition, the protein expression levels of Wnt1, $\beta$-catenin and DVL2 significantly increased $(\mathrm{P}<0.01)$ following mechanical treatment, particularly after $6 \mathrm{~h}$ compression treatment at $0.5 \mathrm{MPa}$ (Figs. 2C and D). Furthermore, $6 \mathrm{~h}$ compressive load reduced the protein expression levels of $\mathrm{p}-\beta$-catenin at $0.5 \mathrm{MPa}$, decreasing the ratio of $\mathrm{p}-\beta$-catenin $/ \beta$-catenin $(\mathrm{P}<0.01)$, which suggested that compression stabilized $\beta$-catenin by inhibiting its phosphorylation at residues Ser33/37/Thr41. These results indicated that compressive load increased expression of key regulators of the Wnt/ $\beta$-catenin signaling pathway, thus promoting osteoblast differentiation.

Subsequently, DKK-1 was utilized to inhibit the binding of Wnt ligands to Lrp5, decreasing the protein expression of $\beta$-catenin and increasing $\mathrm{p}-\beta$-catenin $/ \beta$-catenin, with 
$\mathbf{A}$

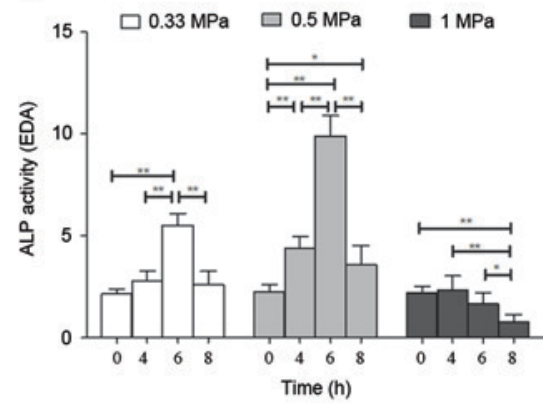

D

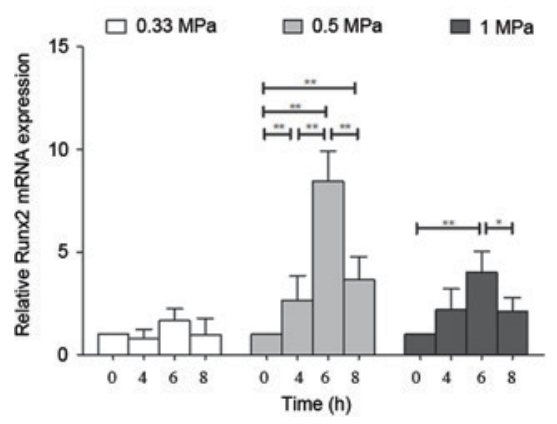

B

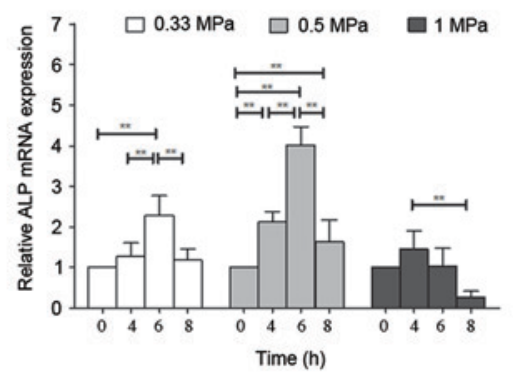

$\mathbf{E}$

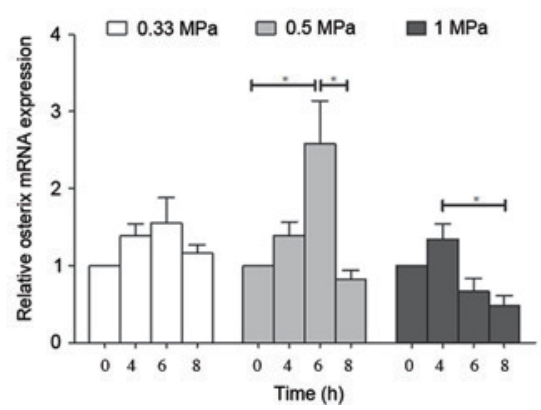

C

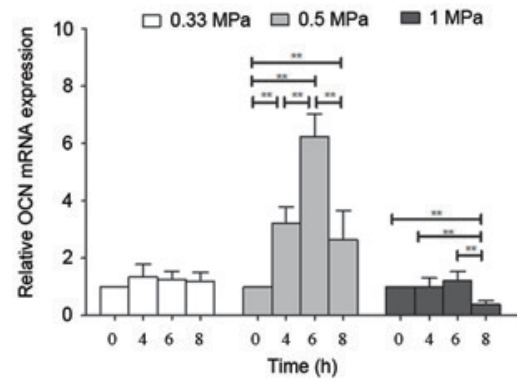

Figure 1. Effect of cyclic compressive loading on osteoblast differentiation in MC3T3-E1 cells. Using a 3D scaffold model, cells were exposed to compressive loads of $0.33,0.5$ or $1 \mathrm{MPa}$ for $0,4,6$ or $8 \mathrm{~h}$. (A) ALP activity was measured. mRNA expression levels of the osteoblast differentiation-related genes (B) ALP (C) $O C N$ (D) Run $x 2$ and (E) $O s x$ were determined by reverse transcription-quantitative polymerase chain reaction, relative to GAPDH. Data are expressed as the mean \pm standard deviation of 3 independent experiments. ${ }^{~} \mathrm{P}<0.05 ;{ }^{* *} \mathrm{P}<0.01$. ALP, alkaline phosphatase; OCN, osteocalcin; Runx2, runt-related transcription factor 2; Osx, osterix.

A

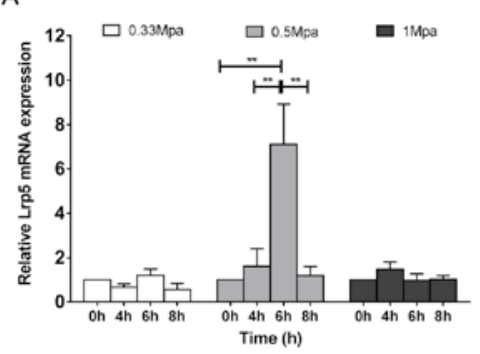

C

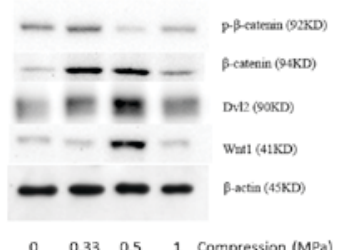

$\begin{array}{lllll}0 & 0.33 & 0.5 & 1 & \text { Compression }(\mathrm{MPa})\end{array}$

D

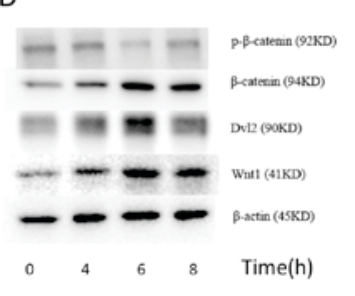

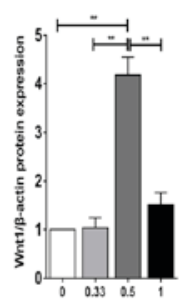

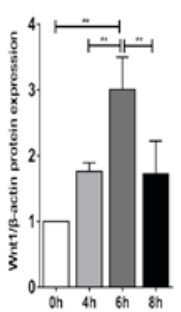

B
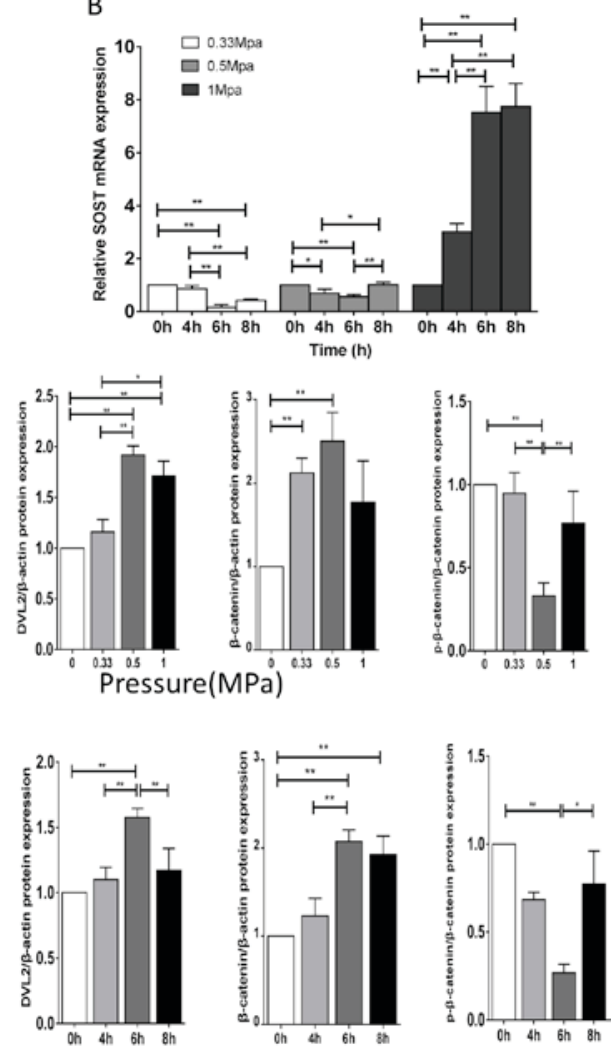

Time $(\mathrm{h})$

Figure 2. Effect of cyclic compressive load on Wnt/ß-catenin signaling in MC3T3-E1 cells. Using a 3D scaffold model, cells were exposed to compressive loads of $0.33,0.5$ or $1 \mathrm{MPa}$ for $0,4,6$ or $8 \mathrm{~h}$. mRNA expression levels of (A) $\operatorname{Lrp} 5$ and (B) $S O S T$ were determined by reverse transcription-quantitative polymerase chain reaction. Protein expression levels of p- $\beta$-catenin, $\beta$-catenin, DVL2 and Wnt1 were evaluated by western blotting comparing (C) different compression pressures $(\mathrm{MPa})$ for $6 \mathrm{~h}$ and (D) different time points with $0.5 \mathrm{MPa} ; \beta$-actin served as an internal control. Bands were quantified via densitometry to obtain relative protein expression levels. Data are expressed as the mean \pm standard deviation of three independent experiments. ${ }^{*} \mathrm{P}<0.05 ;{ }^{* *} \mathrm{P}<0.01$. Lrp5, low density lipoprotein receptor-related protein 5; SOST, sclerostin; p, phosphorylated; DVL2, disheveled segment polarity protein-2; Wnt1, wingless-type. 

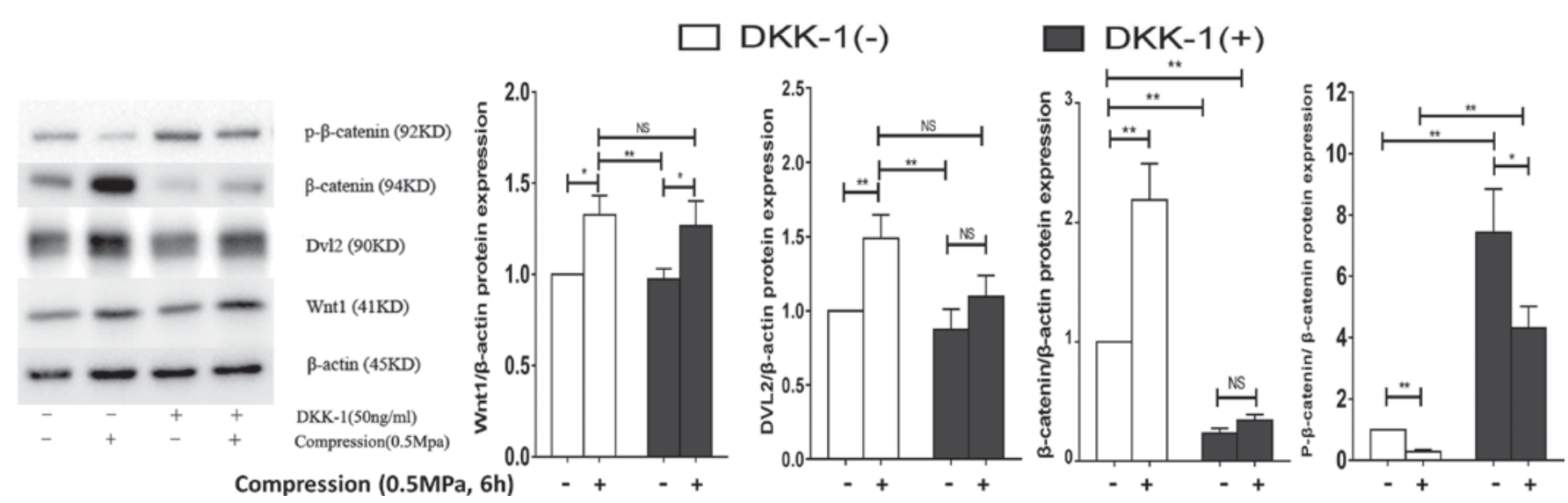

Figure 3. DKK-1 decreases but does not prevent load-induced activation of the Wnt/ $\beta$-catenin signaling pathway. The low density lipoprotein receptor-related protein 5 inhibitor DKK-1 was used $1 \mathrm{~h}$ prior to mechanical treatment to evaluate the potential role of Wnt/ $\beta$-catenin signaling in load-induced osteoblast differentiation. The effect of compressive load on the protein expression levels of $p-\beta$-catenin, $\beta$-catenin, DVL2 and Wnt1, were evaluated by western blotting; $\beta$-actin served as an internal control. Bands were quantified via densitometry to obtain relative protein expression levels. Data are expressed as the mean \pm standard deviation of three independent experiments. ${ }^{*} \mathrm{P}<0.05 ;{ }^{* *} \mathrm{P}<0.01$. NS, not significant; DKK-1, Dickkopf-related protein 1; Wnt1, wingless-type; p, phosphorylated; DVL2, disheveled segment polarity protein- 2 .

no change in Wnt1 or DVL2. Notably, compression loading $(0.5 \mathrm{MPa}, 6 \mathrm{~h})$ and DKK-1 treatment stimulated a significant increase in the protein expression levels of Wnt1 $(\mathrm{P}<0.05)$, decrease in $\mathrm{p}-\beta$-catenin $/ \beta$-catenin $(\mathrm{P}<0.05)$ and no change in $\beta$-catenin or DVL2 when compared with DKK-1 treatment without compression loading (Fig. 3). Therefore, this suggested that DKK-1 decreased but did not prevent compressive load-induced Wnt/ $\beta$-catenin signaling.

\section{Discussion}

Published data have demonstrated that bone cells respond to mechanical load, including tension, compression, hydrostatic pressure and fluid shear stress, which regulate osteoblast differentiation in vitro $(6,8,10,32)$. However, the majority of these studies investigated the effect of loading on monolayer cell cultures. In the present study, a 3D in vitro model was applied to determine the effect of cyclic compressive load on osteoblast differentiation. Compressive load increased ALP activity and mRNA expression levels of ALP, OCN, Runx2 and Os $x$ in osteoblasts, indicating that mechanical load stimulates osteoblast differentiation, leading to osteoblast maturation and bone formation.

Mechanical loads of 2,000-4,000 $\mu$ strain on long bones from physical activity may promote bone remodeling, and $1,500 \mu$ strain is considered to be the threshold for promoting this in vivo $(33,34)$. However, it is difficult to compare the magnitude of strain in vitro with that in vivo, and the effect of magnitude of mechanical stress on osteoblast differentiation remains to be fully elucidated $(8,28,32)$. Thus, the present study investigated the effect of three different magnitudes of compressive load on osteoblast differentiation. Data revealed that $0.5 \mathrm{MPa}$ compression effectively increased ALP activity and the mRNA expression levels of osteoblast differentiation markers. Compression at $0.33 \mathrm{MPa}$ promoted ALP expression and activity; however, to a lesser extent than $0.5 \mathrm{MPa}$, whereas $1 \mathrm{MPa}$ resulted in a reduction in ALP mRNA expression levels and activity. This is consistent with a previous study that demonstrated that Runx2 was up-regulated following
0.8 and $5 \%$ elongation for $6 \mathrm{~h}$, and downregulated following 5, 10 and 15\% elongation for 24 and $48 \mathrm{~h}$ (26). Sanchez et al (28) demonstrated that 1-1.7 MPa compression lead to an increase in the mRNA expression levels of IL-6 and cyclooxygenase-2, and a decrease in the mRNA expression level of OPG in osteoblasts, which may downregulate bone formation and promote osteoclast differentiation. The results of the present study indicated that compressive load promotes osteoblast differentiation in bone cells when an optimal magnitude of $0.5 \mathrm{MPa}(\sim 3 \%$ elongation strain) is applied; however, greater magnitudes prevent bone formation.

In the present study, the effect of different durations of compressive load on osteoblast differentiation was additionally investigated. Results demonstrated that $6 \mathrm{~h}$ compressive load effectively promoted factors involved in osteoblast differentiation, and was more efficacious than durations of 4 or $8 \mathrm{~h}$. A compression time of $8 \mathrm{~h}$ reduced the expression levels of osteoblast differentiation-associated genes in MC3T3-E1 cells following treatment with a high magnitude of $1 \mathrm{MPa}$. Koike et al (26) reported that high strain magnitudes downregulated Runx 2 mRNA expression levels after 24 and $48 \mathrm{~h}$ in the stromal cell line, ST2, which is consistent with data obtained in the present study. Sittichockechaiwut et al (8) demonstrated that $2 \mathrm{~h}$ of $5 \%$ elongation compression on MLO-A5 cells increased the mRNA expression levels of type 1 collagen, osteopontin and OCN, and had a substantial effect on osteoblast differentiation. These results indicated that the response of bone cells to compressive load is dependent on a combination of magnitude and duration. However, different cell types have different responses to mechanical stress, which may lead to variable results.

The Wnt/ $\beta$-catenin signaling pathway is activated when Wnt ligands, including Wnt1, Wnt3a and Wnt8 bind to the frizzled (Fzd) receptors and coreceptors, Lrp5 and Lrp6. The Wnt-Fzd-Lrp complex subsequently activates $\beta$-catenin signaling (35). $\beta$-catenin is stabilized when localized in the cytoplasm; however, its translocation to the nucleus leads to activation of Wnt signaling $(36,37)$, which regulates osteoblastogenesis (13-18), promotion of bone formation and 
repression of bone resorption (38). Studies have demonstrated that mechanical strain enhances the mRNA expression levels of Wnt3a and Wnt10b (39); however, to the best of our knowledge, no study to date has investigated whether compressive strain increases expression levels of Wnt1. In the present study, $0.5 \mathrm{MPa}$ compressive load significantly increased the protein expression level of Wnt1, and $6 \mathrm{~h}$ mechanical load was most effective. This condition additionally increased the expression levels of osteoblast differentiation markers, which suggested that initial activation of $\mathrm{Wnt} / \beta$-catenin signaling may be involved in compression-induced osteoblast differentiation. A previous study has revealed that compressive load activated DVL2, which promoted the stabilization of $\beta$-catenin by disruption of the $\beta$-catenin destruction complex (38), and activated the $\mathrm{Wnt} / \beta$-catenin signaling pathway. In the present study, compressive load led to an increase in the protein expression levels of $\beta$-catenin and decreased the inactivation of $\beta$-catenin, as ascertained by measuring the protein expression levels of $\mathrm{p}$ - $\beta$-catenin. In addition, compression enhanced mRNA expression levels of Lrp5 and decreased those of SOST. These results suggested that Wnt/ $\beta$-catenin signaling serves a role in the response to compressive load in MC3T3-E1 cells and osteoblast differentiation.

DKK-1 inhibits Wnt/ $\beta$-catenin signaling by binding to Lrp5/6. When treated with DKK-1, compression loading $(0.5 \mathrm{MPa}, 6 \mathrm{~h})$ stimulated a significant increase in the protein expression levels of Wnt1, and a significant decrease in the ratio of $p$ - $\beta$-catenin/ $\beta$-catenin when compared to DKK-1 treatment without compression loading; however, the expression level of DVL2 was not altered. These results suggested that signaling pathways other than Wnt may be contributing to load-induced osteoblast differentiation (40). Previous studies have demonstrated that mechanical stimuli activated protein kinase $B$, inhibited glycogen synthase kinase $3 \beta$ via phosphorylation, which directly activated $\beta$-catenin $(23,41)$. Therefore, the osteoblast response to compressive loading may be regulated by cross-talk between different signaling pathways. A report by Ponik et al (6) demonstrated that Lrp5-positive transgenic mice were more sensitive to mechanical load, and this was associated with upregulated Wnt target gene expression. Therefore, Wnt/ $\beta$-catenin signaling may regulate osteoblast differentiation in response to compressive load.

In conclusion, the present study demonstrated that compressive loading stimulates osteoblast differentiation in a magnitude-and duration-dependent manner.The Wnt/ $\beta$-catenin signaling pathway may serve a role in load-induced osteoblast differentiation; however, other signaling pathways are likely to be involved. The findings of the present study provide further understanding of the effect of compressive load on osteoblast differentiation and bone formation, which may ultimately help prevent the development of osteoporosis.

\section{Acknowledgements}

The present study was supported by the National Natural Science Foundation of China (grant no. 81170323), the Shanghai Key Laboratory of Human Sport Competence Development and Maintenance (Shanghai University of Sport; grant no. 11DZ2261100) and the Innovation Project of Shanghai University of Sport Graduate Education (grant no. yjscx2015007).

\section{References}

1. NIH Consensus Development Panel on Osteoporosis Prevention, Diagnosis, and Therapy: Osteoporosis prevention, diagnosis, and therapy. JAMA 285: 785-795, 2001.

2. Bliuc D, Alarkawi D, Nguyen TV, Eisman JA and Center JR: Risk of subsequent fractures and mortality in elderly women and men with fragility fractures with and without osteoporotic bone density: The dubbo osteoporosis epidemiology study. J Bone Miner Res 30: 637-646, 2015.

3. Zaidi M: Skeletal remodeling in health and disease. Nature Med 13: 791-801, 2007.

4. Lang T, LeBlanc A, Evans H, Lu Y, Genant $\mathrm{H}$ and $\mathrm{Yu}$ A: Cortical and trabecular bone mineral loss from the spine and hip in long-duration spaceflight. J Bone Miner Res 19: 1006-1012, 2004.

5. Kim CH, Kim KH and Jacobs CR: Effects of high frequency loading on RANKL and OPG mRNA expression in ST-2 murine stromal cells. BMC Musculoskelet Disord 10: 109, 2009.

6. Ponik SM, Triplett JW and Pavalko FM: Osteoblasts and osteocytes respond differently to oscillatory and unidirectional fluid flow profiles. J Cell Biochem 100: 794-807, 2007.

7. Carinci F, Pezzetti F, Spina AM, Palmieri A, Carls F, Laino G, De Rosa A, Farina E, Illiano F, Stabellini G, et al: An in vitro model for dissecting distraction osteogenesis. J Craniofac Surg 16: 71-79, 2005.

8. Sittichockechaiwut A, Scutt AM, Ryan AJ, Bonewald LF and Reilly GC: Use of rapidly mineralising osteoblasts and short periods of mechanical loading to accelerate matrix maturation in 3D scaffolds. Bone 44: 822-829, 2009.

9. Zhong Z, Zeng XL, Ni JH and Huang XF: Comparison of the biological response of osteoblasts after tension and compression. Eur J Orthod 35: 59-65, 2013.

10. Thompson WR, Rubin CT and Rubin J: Mechanical regulation of signaling pathways in bone. Gene 503: 179-193, 2012.

11. Robling AG, Niziolek PJ, Baldridge LA, Condon KW, Allen MR, Alam I, Mantila SM, Gluhak-Heinrich J, Bellido TM, Harris SE and Turner $\mathrm{CH}$ : Mechanical stimulation of bone in vivo reduces osteocyte expression of Sost/sclerostin. J Biol Chem 283: 5866-5875, 2008.

12. Wozniak M, Fausto A, Carron CP, Meyer DM and Hruska KA: Mechanically strained cells of the osteoblast lineage organize their extracellular matrix through unique sites of alphavbeta3-integrin expression. J Bone Miner Res 15: 1731-1745, 2000.

13. Day TF, Guo X, Garrett-Beal L and Yang Y: Wnt/beta-catenin signaling in mesenchymal progenitors controls osteoblast and chondrocyte differentiation during vertebrate skeletogenesis. Dev Cell 8: 739-750, 2005.

14. Bennett CN, Longo KA, Wright WS, Suva LJ, Lane TF, Hankenson KD and MacDougald OA: Regulation of osteoblastogenesis and bone mass by Wnt10b. Proc Natl Acad Sci USA 102: 3324-3329, 2005.

15. Canalis E: Wnt signalling in osteoporosis: Mechanisms and novel therapeutic approaches. Nat Rev Endocrinol 9: 575-583, 2013.

16. Kato M, Patel MS, Levasseur R, Lobov I, Chang BH, Glass DA II, Hartmann C, Li L, Hwang TH, Brayton CF, et al: Cbfa1-independent decrease in osteoblast proliferation, osteopenia and persistent embryonic eye vascularization in mice deficient in Lrp5, a Wnt coreceptor. J Cell Biol 157: 303-314, 2002.

17. Krishnan V, Bryant HU and Macdougald OA: Regulation of bone mass by Wnt signaling. J Clin Invest 116: 1202-1209, 2006.

18. Gong Y, Slee RB, Fukai N, Rawadi G, Roman-Roman S, Reginato AM, Wang H, Cundy T, Glorieux FH, Lev D, et al: LDL receptor-related protein 5 (LRP5) affects bone accrual and eye development. Cell 107: 513-523, 2001.

19. Cui Y, Niziolek PJ, MacDonald BT, Zylstra CR, Alenina N, Robinson DR, Zhong Z, Matthes S, Jacobsen CM, Conlon RA, et al: Lrp5 functions in bone to regulate bone mass. Nat Med 17: 684-691, 2011.

20. Lian JB, Stein GS, Javed A, van Wijnen AJ, Stein JL, Montecino M, Hassan MQ, Gaur T, Lengner CJ and Young DW: Networks and hubs for the transcriptional control of osteoblastogenesis. Rev Endocr Metab Disord 7: 1-16, 2006. 
21. Javed A, Bae JS, Afzal F, Gutierrez S, Pratap J, Zaidi SK, Lou Y, van Wijnen AJ, Stein JL, Stein GS and Lian JB: Structural coupling of Smad and Runx2 for execution of the BMP2 osteogenic signal. J Biol Chem 283: 8412-8422, 2008.

22. Sawakami K, Robling AG, Ai M, Pitner ND, Liu D, Warden SJ, Li J, Maye P, Rowe DW, Duncan RL, et al: The Wnt co-receptor LRP5 is essential for skeletal mechanotransduction but not for the anabolic bone response to parathyroid hormone treatment. J Biol Chem 281: 23698-23711, 2006.

23. Sen B, Guilluy C, Xie Z, Case N, Styner M, Thomas J, Oguz I, Rubin C, Burridge K and Rubin J: Mechanically induced focal adhesion assembly amplifies anti-adipogenic pathways in mesenchymal stem cells. Stem cells 29: 1829-1836, 2011.

24. Tu X, Rhee Y, Condon KW, Bivi N, Allen MR, Dwyer D, Stolina M, Turner CH, Robling AG, Plotkin LI and Bellido T: Sost downregulation and local Wnt signaling are required for the osteogenic response to mechanical loading. Bone 50: 209-217, 2012.

25. Sanchez C, Pesesse L, Gabay O, Delcour JP, Msika P, Baudouin C and Henrotin YE: Regulation of subchondral bone osteoblast metabolism by cyclic compression. Arthritis Rheum 64: 1193-1203, 2012.

26. Koike M, Shimokawa H, Kanno Z, Ohya K and Soma K: Effects of mechanical strain on proliferation and differentiation of bone marrow stromal cell line ST2. J Bone Miner Metab 23: 219-225, 2005.

27. Jacobs C, Grimm S, Ziebart T, Walter C and Wehrbein H: Osteogenic differentiation of periodontal fibroblasts is dependent on the strength of mechanical strain. Arch Oral Biol 58: 896-904, 2013.

28. Sanchez C, Gabay O, Salvat C, Henrotin YE and Berenbaum F: Mechanical loading highly increases IL- 6 production and decreases OPG expression by osteoblasts. Osteoarthritis Cartilage 17: 473-481, 2009.

29. Fermor B, Weinberg JB, Pisetsky DS, Misukonis MA, Banes AJ and Guilak F: The effects of static and intermittent compression on nitric oxide production in articular cartilage explants. J Orthop Res 19: 729-737, 2001.

30. Xue Y, Yan Y, Gong H, Fang B, Zhou Y, Ding Z, Yin P, Zhang G, Ye Y, Yang $\mathrm{C}$, et al: Insulin-like growth factor binding protein 4 enhances cardiomyocytes induction in murine-induced pluripotent stem cells. J Cell Biochem 115: 1495-1504, 2014.
31. Lviak KJ and Schmittgen TD: Analysis of relative gene expression data using real-time quantitative PCR and the 2(-Delta Delta C(T)) Method. Methods 25: 402-408, 2001

32. Dumas V, Perrier A, Malaval L, Laroche N, Guignandon A, Vico L and Rattner A: The effect of dual frequency cyclic compression on matrix deposition by osteoblast-like cells grown in 3D scaffolds and on modulation of VEGF variant expression. Biomaterials 30: 3279-3288, 2009.

33. David V, Guignandon A, Martin A, Malaval L, Lafage-Proust MH, Rattner A, Mann V, Noble B, Jones DB and Vico L: Ex Vivo bone formation in bovine trabecular bone cultured in a dynamic 3D bioreactor is enhanced by compressive mechanical strain. Tissue Eng Part A 14: 117-126, 2008.

34. Peptan AI, Lopez A, Kopher RA and Mao JJ: Responses of intramembranous bone and sutures upon in vivo cyclic tensile and compressive loading. Bone 42: 432-438, 2008.

35. Goel S, Chin EN, Fakhraldeen SA, Berry SM, Beebe DJ and Alexander CM: Both LRP5 and LRP6 receptors are required to respond to physiological Wnt ligands in mammary epithelial cells and fibroblasts. J Biol Chem 287: 16454-16466, 2012.

36. Colaianni G, Cuscito C, Mongelli T, Pignataro P, Tamma R, Oranger A, Colucci S and Grano M: Cellular Mechanisms of Bone Regeneration: Role of Wnt-1 in Bone-Muscle Interaction during Physical Activity39. J Biol Regul Homeost Agents 29 (4 Suppl): S39-S45, 2015.

37. MacDonald BT, Tamai K and He X: Wnt/beta-catenin signaling: Components, mechanisms, and diseases. Dev Cell 17: 9-26, 2009.

38. Baron R and Kneissel M: WNT signaling in bone homeostasis and disease: From human mutations to treatments. Nat Med 19: 179-192, 2013.

39. Robinson JA, Chatterjee-Kishore M, Yaworsky PJ, Cullen DM, Zhao W, Li C, Kharode Y, Sauter L, Babij P, Brown EL, et al: Wnt/beta-catenin signaling is a normal physiological response to mechanical loading in bone. J Biol Chem 281: 31720-31728, 2006.

40. He XC, Zhang J, Tong WG, Tawfik O, Ross J, Scoville DH, Tian Q, Zeng X, He X, Wiedemann LM, et al: BMP signaling inhibits intestinal stem cell self-renewal through suppression of Wnt-beta-catenin signaling. Nat Genet 36: 1117-1121, 2004.

41. Case N, Ma M, Sen B, Xie Z, Gross TS and Rubin J: Beta-catenin levels influence rapid mechanical responses in osteoblasts. J Biol Chem 283: 29196-29205, 2008. 